\title{
A New Approach to High Modulus, High Tenacity Fibers
}

\author{
S. OZAWA \\ Central Research Laboratories, Teijin Limited, \\ Hino, Tokyo 191, Japan
}

(Received August 17, 1986)

\begin{abstract}
An overview to TECHNORA ${ }^{\circledR}$ is made in emphasis on its molecular design concept and its physical and chemical properties.

KEY WORDS TECHNORA ${ }^{\circledR}$ / Aramid Fiber / Terephthalamide / 3,4'Diaminodiphenyl Ether /
\end{abstract}

A long dream of fiber scientists was to bring the mechanical strength and toughness of man-made fibers as close as possible to those of constituent molecules. Tenacity of $10 \mathrm{~g} \mathrm{~d}^{-1}$ had been a realistic barrier in spite of extensive technological efforts until scientists of du Pont Company made the first break-through with commercial success of KEVLAR ${ }^{\circledR}$ from poly ( $p$-phenylene terephthalamide) (PPTA). Another achievement to be noted was the fibers from linear polyethylene of super-high molecular weight. It first demonstrated the fact that even flexible, low melting polymer could give such super-high tenacity and toughness. In this paper I would like to introduce such a super-fiber derived from copolymers of aramid with emphasis on understanding its unique chemical resistance. The fiber is now named TECHNORA ${ }^{\circledR}$ and to be commercialized next summer.

\section{RESULTS AND DISCUSSION}

\section{Polymer Skeleton}

It has been said that the outstanding tensile properties of KEVLAR ${ }^{\circledR}$ are derived from its rigid and rather straight molecular structure and its well aligned crystallites consisting of extended molecular chains. Our ideas were that even with those very high values of its tensile properties, their levels were still only fractions of those of constituent molecules. Therefore, if molecules could really be aligned and fixed, there was no reason why we should not be able to obtain a super-fiber from other polymers, regardless of their kind.

The basic considerations we took in search for such an opportunity are summarized in Table I. ${ }^{1}$ As shown in the table, each of the objectives requires conflicting molecular structures, which needed to compromise into one possible polymer backbone. Our target was a fiber which has (a) comparable tensile properties of $\operatorname{KEVLAR}^{\circledR}$, (b) substantial heat resistance, (c) solubility in organic solvents, and (d) reasonable economics.

One prior art along a similar line was shown in Figure 1 by Bayer A. G., ${ }^{2}$ in which they insisted that the presence of one metaconfiguration is preferred in their fourphenylene aramid. We studied copolymer effects on the solubility and the tensile property of PPTA fibers by incorporating various simple diamines and diacyl compounds. The results indicated that at $10 \mathrm{~mol} \%$ copolymerization the solubility was not much improved, while the fiber tenacity was reduced, only except for the case of 3,4'-diaminodiphenyl ether $\left(3,4^{\prime}\right.$-ODA). ${ }^{3}$ Table II summarizes the results of some detailed studies on copoly- 
terephthalamides of $p$-phenylene diamine and $3,4^{\prime}$-ODA. Although aramids of dissymmetrical components including 3,4'-ODA seemed to be a rather familiar subject in USSR, ${ }^{4}$ no works were associated with fibers.

We had not so much expected, but even the $50 \mathrm{~mol} \%$ copolymer of random nature surprisingly gave a super-fiber with satisfactory balance of the physical properties. A possible explanation will be that the slimness and the flexibility of $3,4^{\prime}$-ODA terephthalamide do help and do not interfere alignment of the molecules. Also, the $p$-phenylene terephthal-

Table I. Polymer design for TECHNORA ${ }^{\circledR}$

\begin{tabular}{ll}
\hline \multicolumn{1}{c}{ Objectives } & \multicolumn{1}{c}{ Molecular design } \\
\hline $\begin{array}{c}\text { Thermal } \\
\text { stability }\end{array}$ & $\begin{array}{l}\text { Wholly aromatic polyamide. } \\
\text { Absence of unstable linkage like } \\
\text { urethane, urea, alkylene, etc. }\end{array}$ \\
\hline Solubility & $\begin{array}{l}\text { Random copolymer with dissymmetrical } \\
\text { units. } \\
\text { Inclusion of }-\mathrm{O}-,-\mathrm{CO}-,-\mathrm{SO}_{2}-, \text { etc. }\end{array}$ \\
\hline $\begin{array}{c}\text { Amides rather than esters. } \\
\text { Heat }\end{array}$ & $\begin{array}{l}\text { High molecular weight. } \\
\text { Enhanced chain flexibility by incorpo- } \\
\text { rating }-\mathrm{O}-,-\mathrm{CO}-,-\mathrm{SO}_{2}-\text {, etc. into } \\
\text { polymer chain. }\end{array}$ \\
\hline $\begin{array}{c}\text { Dimensional } \\
\text { stability }\end{array}$ & $\begin{array}{l}\text { Rigid molecular chain. } \\
\text { Crystallinity by regular sequence in } \\
\text { polymer. }\end{array}$ \\
\hline
\end{tabular}

amide unit is effective enough to form intermolecular junctions, even by scattered presence in the $50 \%$ copolymer chain, due to its rigid and extended nature.

The differential scanning calorimetric measurements ${ }^{5}$ of the $50 \%$ copolymer gave a simple sum of two endo-therms at 520 and $570^{\circ} \mathrm{C}$, corresponding to the homo-polymer melting points of $3,4^{\prime}$-ODA terephthalamide and PPTA, respectively, indicating the presence of two distinct crystal structures. This was also observable by $\mathrm{X}$-ray diffraction of the fiber.

The similar ideas were later tested for polyarylates $^{6,7}$ which showed significantly high tensile properties when fibers were properly prepared, although they could not avoid the

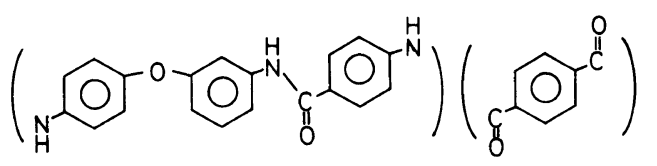

Fiber, wet spun and drawn $(\times 6.0)$ $T, 7.2 \mathrm{~g} / \mathrm{dtex} ; E, 2.0 \% ; M, 9,200 \mathrm{~kg} \mathrm{~mm}^{-2}$.

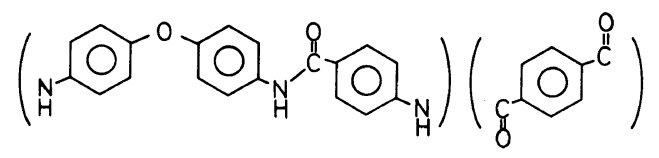

Fiber, wet spun and drawn $(\times 2.0)$ $T, 2.9 \mathrm{~g} / \mathrm{dtex} ; E, 3.5 \% ; M, 900 \mathrm{~kg} \mathrm{~mm}^{-2}$.

Figure 1. Bayer's aramid fiber [Japan-Tokukaisho 4835117, May 22, (1973)].

Table II. Copoly(terephthalamide) of $p$-phenylenediamine and 3,4'-diamino-diphenyl ether ${ }^{\mathbf{a}}$

\begin{tabular}{|c|c|c|c|c|c|}
\hline \multirow{2}{*}{$x$} & \multicolumn{5}{|c|}{ Copolymer ratio (PPTA mol\%) } \\
\hline & 0 & 30 & 50 & 70 & 100 \\
\hline Inherent viscosity (typical value) & 2.5 & 3.0 & 3.5 & 4.0 & 5.5 \\
\hline Dope concn. (wt $\%$ in $N$-methylpyrrolidone) & 10 & 7 & 6 & 5 & 0 \\
\hline Sample draw temperature $\left({ }^{\circ} \mathrm{C}\right)$ & 400 & 480 & 500 & 510 & - \\
\hline Sample draw ratio & 3.5 & 10 & 8.5 & 6.0 & - \\
\hline Fiber tenacity $\left(\mathrm{g} \mathrm{d}^{-1}\right)$ & 11 & 23 & 26 & 20 & $(23)$ \\
\hline Fiber elongation $(\%)$ & 8 & 4 & 4 & 4 & (3) \\
\hline Fiber modulus $\left(\mathrm{g} \mathrm{d}^{-1}\right)$ & 250 & 550 & 620 & 660 & $(700)$ \\
\hline
\end{tabular}




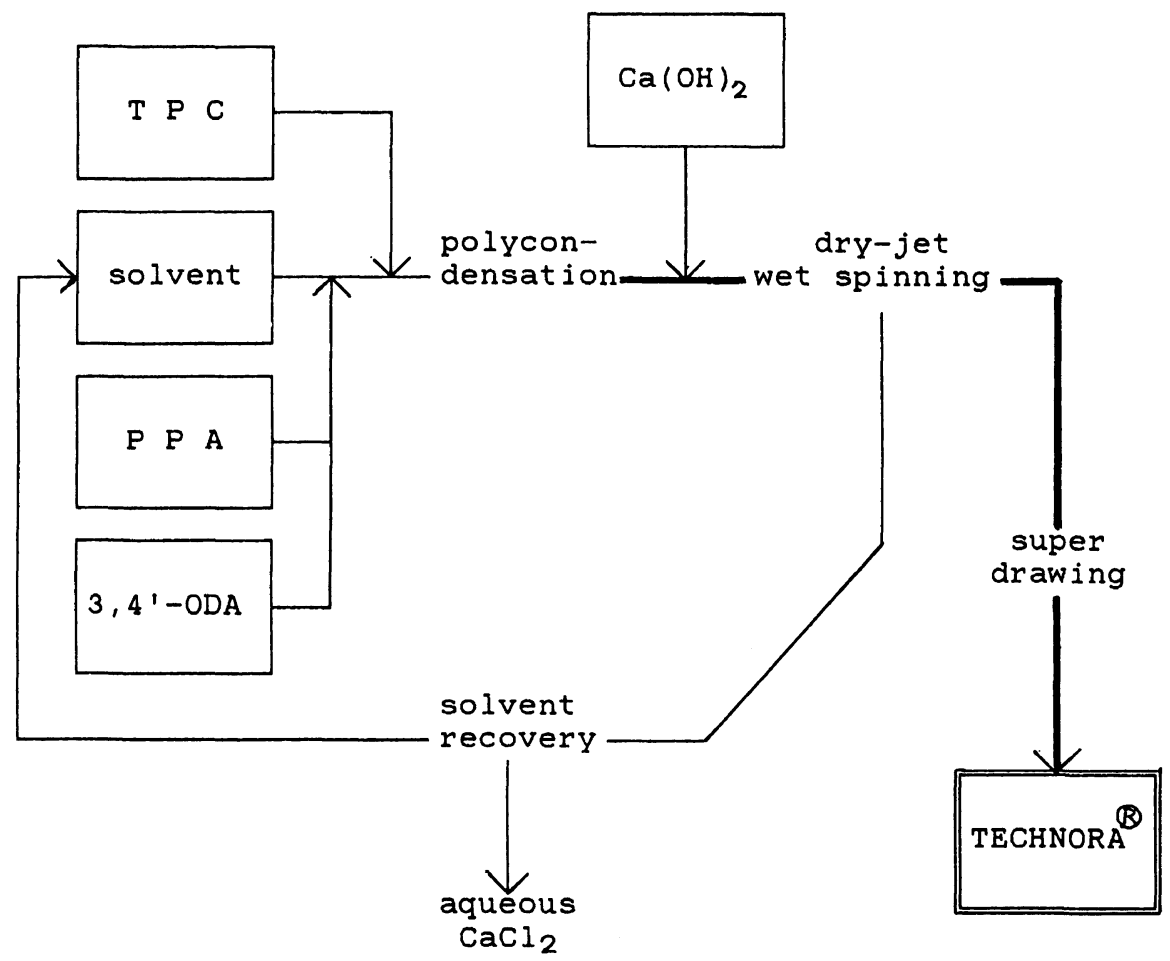

Figure 2. TECHNORA $^{\circledR}$ process.

slow post-cure process.

\section{Manufacturing Process}

Construction of the manufacturing process for TECHNORA ${ }^{\circledR}$ is schematically depicted in Figure 2. ${ }^{8}$ It takes full advantages of the $50 \mathrm{~mol} \%$ copoly-terephthalamide of $p$ phenylenediamine and 3,4'-ODA (HM-50). The polymer is soluble in a single solvent like $N$-methyl-pyrrolidone. The solution, when neutralized, is stable enough to be carried out directly to the spinning process, where it is introduced into an aqueous coagulation bath. The gel fiber formed is then subjected to solvent extraction, drawing, and finish to give the final product.

Since only one solvent is used throughout the process and there is no isolation of the polymer, the process becomes simple and straightforward. No use of a strong acid not only greatly simplified the solvent recovery, but also makes TECHNORA ${ }^{\circledR}$ fibers free of the residual acid.

\section{Physical Properties of the Fiber}

Tensile properties and their thermal dependence of typical TECHNORA ${ }^{\circledR}$ fibers are summarized in Table III and Figure 3..$^{9}$ Their levels are no less than those of crystalline PPTA fibers in the practical temperature range. Tenacity retention of twine cords after 2000 times of bending motion were compared, and summarized below together with the data of abrasive wear resistance in terms of the number of frictions before rupture ${ }^{10}$ :

\begin{tabular}{|c|c|c|c|}
\hline \multirow{2}{*}{ Cord } & \multirow{2}{*}{$\begin{array}{c}\text { Tenacity } \\
\text { retention } \\
\text { after bending } \\
\text { wear }\end{array}$} & \multicolumn{2}{|c|}{$\begin{array}{l}\text { Frictional wear } \\
\text { resistance }\end{array}$} \\
\hline & & $\begin{array}{l}\text { Against } \\
\text { steel }\end{array}$ & $\begin{array}{l}\text { Against } \\
\text { itself }\end{array}$ \\
\hline TECHNORA $^{\circledR}$ & $52 \%$ & 884 & 287 \\
\hline PPTA & $36 \%$ & 234 & 120 \\
\hline
\end{tabular}


Table III. Typical properties of TECHNORA ${ }^{\circledR}$ fiber

\begin{tabular}{|c|c|c|}
\hline \multicolumn{3}{|l|}{ Tensile properties: } \\
\hline Density & $\mathrm{g} \mathrm{cm}^{-3}$ & 1.39 \\
\hline \multirow[t]{2}{*}{ Tenacity } & $\mathrm{gd}^{-1}$ & 25 \\
\hline & $\mathrm{kg} \mathrm{mm}^{-2}$ & 310 \\
\hline \multirow[t]{2}{*}{ Tensile modulus } & $\mathrm{gd}^{-1}$ & 570 \\
\hline & $\mathrm{kg} \mathrm{mm}^{-2}$ & 7,100 \\
\hline Elongation at break & $\%$ & 4.4 \\
\hline \multicolumn{3}{|l|}{ Thermal behavior: } \\
\hline Melting point & ${ }^{\circ} \mathrm{C}$ & $\begin{array}{l}>500 \\
\text { (decomp. })\end{array}$ \\
\hline Thermal shrinkage at $300^{\circ} \mathrm{C}$ & $\%$ & $<0.5$ \\
\hline Tenacity at $200^{\circ} \mathrm{C}$ & $\mathrm{gd}^{-1}$ & 16 \\
\hline Tensile modulus at $200^{\circ} \mathrm{C}$ & $\mathrm{gd}^{-1}$ & 490 \\
\hline Flammability: & L.O.I. & 25 \\
\hline \multicolumn{3}{|c|}{$\begin{array}{l}\text { Chemical resistance: } \\
\text { (tenacity retention after } 100 \mathrm{~h} \text { of exposure) }\end{array}$} \\
\hline $\operatorname{Air}\left(200^{\circ} \mathrm{C}\right)$ & $\%$ & 95 \\
\hline Water $\left(120^{\circ} \mathrm{C}\right)$ & $\%$ & 97 \\
\hline $40 \% \mathrm{H}_{2} \mathrm{SO}_{4}$ aq $\left(95^{\circ} \mathrm{C}\right)$ & $\%$ & 89 \\
\hline $10 \% \mathrm{NaOH}$ aq $\left(95^{\circ} \mathrm{C}\right)$ & $\%$ & 84 \\
\hline
\end{tabular}

Under a microscope, the difference seemed to be related largely to the tendency of the cord to fibrillate. One may attribute the higher fatigue resistance of TECHNORA $^{\circledR}$ to its more flexible polymer chain and its less developed crystal structures.

\section{Chemical Properties}

Other specific features of TECHNORA ${ }^{\circledR}$ are well demonstrated by its chemical resistance. Figure $4^{11}$ shows retention of the inherent viscosity (I.V.) of various aramids dissolved in $98 \% \mathrm{H}_{2} \mathrm{SO}_{4}$, indicating that the aramid containing an ether linkage is rather susceptible to the strong acid than are pure aramids. However, hydrolytic stability of the fibers is entirely different. Figure 5 shows retention of tenacity and I.V. of the residual fiber after immersion in hydrolytic media in comparison with a PPTA fiber. ${ }^{11}$ The results show quick losses both in tenacity and I.V. in case of PPTA, while TECHNORA ${ }^{\circledR}$ remains rather intact both against acid and alkali.

The same holds true even against neutral water. In Figure 6 there is shown the difference

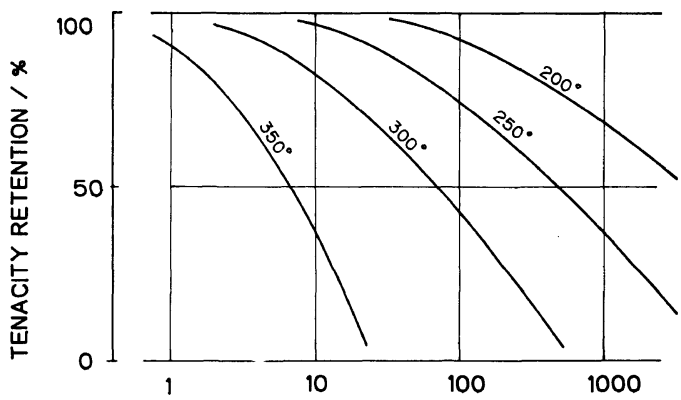

(a) EXPOSURE TIME $/ \mathrm{h}$

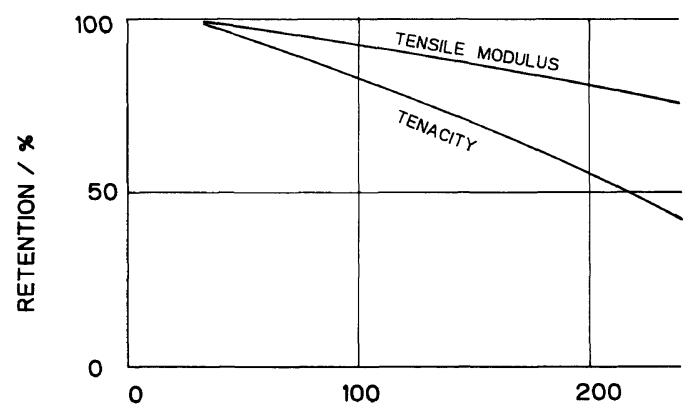

(b) TEMPERATURE $/^{\circ} \mathrm{C}$

Figure 3. Heat (in air) resistance of TECHNORA ${ }^{\circledR}$ fiber.

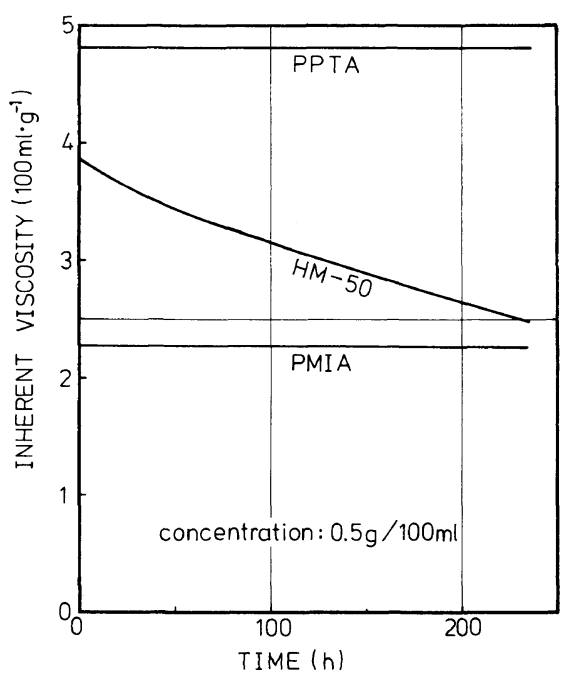

Figure 4. Degradation of aramids in $98 \% \mathrm{H}_{2} \mathrm{SO}_{4}$ at $30^{\circ} \mathrm{C}$.

in the behavior of the two fibers under various conditions. ${ }^{12}$

The similar behavior was also observed in 


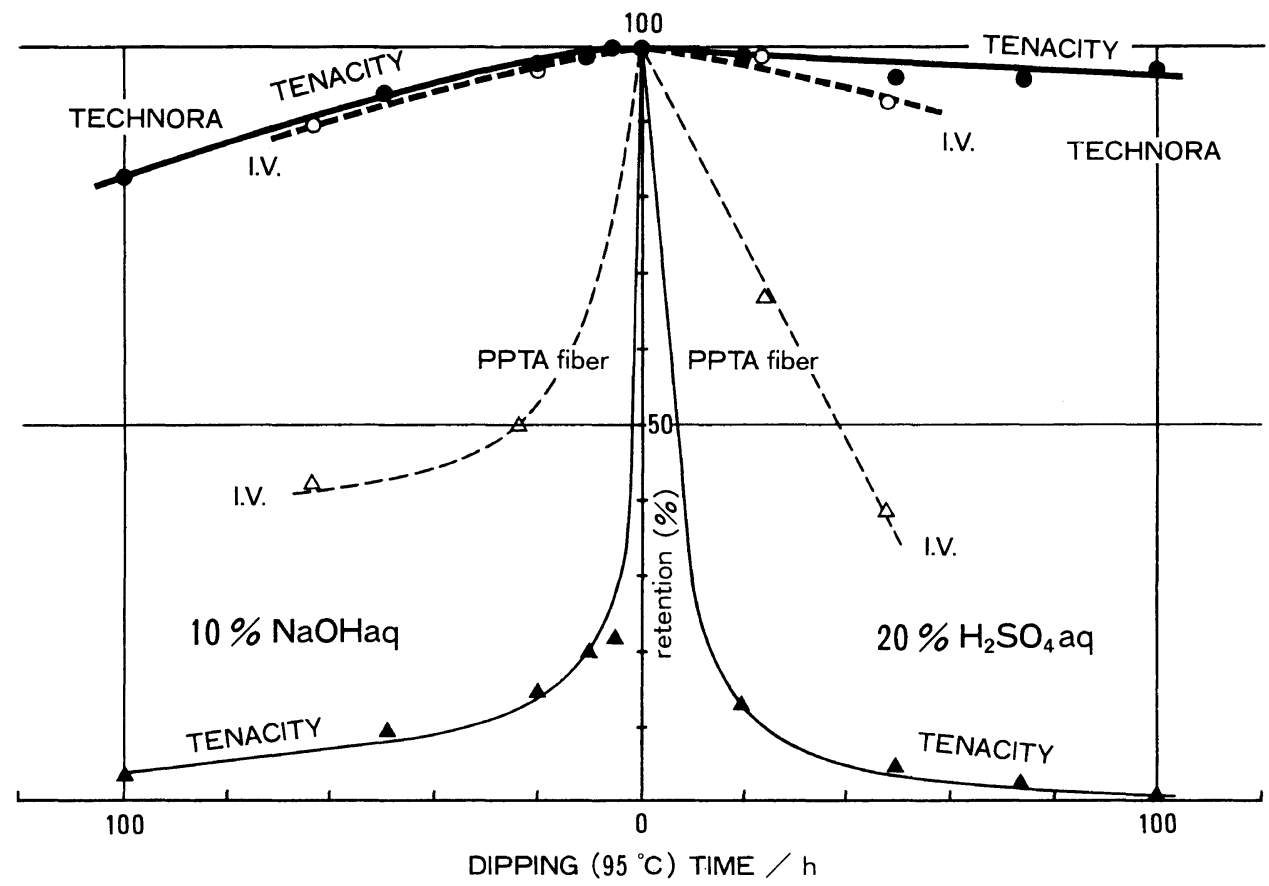

Figure 5. Tenacity retention and degradation of aramid fibers in hydrolyses.

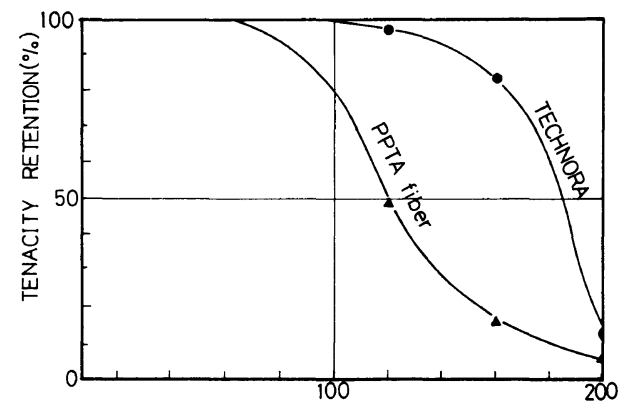

(a) IMMERSION(100h) TEMPERATURE $/{ }^{\circ} \mathrm{C}$

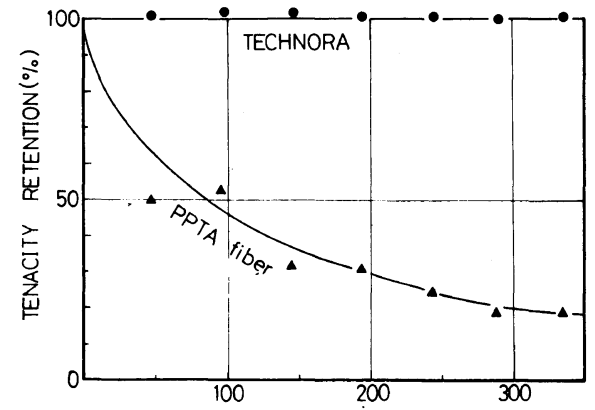

(b) IMMERSED $\left(120^{\circ} \mathrm{c}\right) \quad \mathrm{TIME} / \mathrm{h}$

Figure 6. Hydrolytic resistance of yarns immersed in water. an immersion test in aqueous oxidizing agents. The results against aqueous hypochlorites were summarized in Figure $7^{12}$ suggesting somewhat heterogeneous structure in PPTA fibers. There seemed to be a surface layer and an internal core, the former being very strong mechanically but rather weak hydrolytically or oxidatively, and the latter not much contributing to the fiber tenacity. On the other hand, TECHNORA ${ }^{\circledR}$ seems rather homogeneous, still deviated from the dashed diagonal line though, and more resistant against attack by the chemicals by one order of magnitude.

By SEM observations along with the above experiments, surface etching by the chemicals revealed detailed morphological structures, ${ }^{13}$ which were generally consistent with the work done by C. O. Pruneda et al. ${ }^{14}$ Unusually quick attack by those chemicals seems to suggest that in PPTA fibers rigid and perfect crystallites grow to a certain size, at which molecular chain ends or tightly stretched tie molecules stop further crystal growth. 


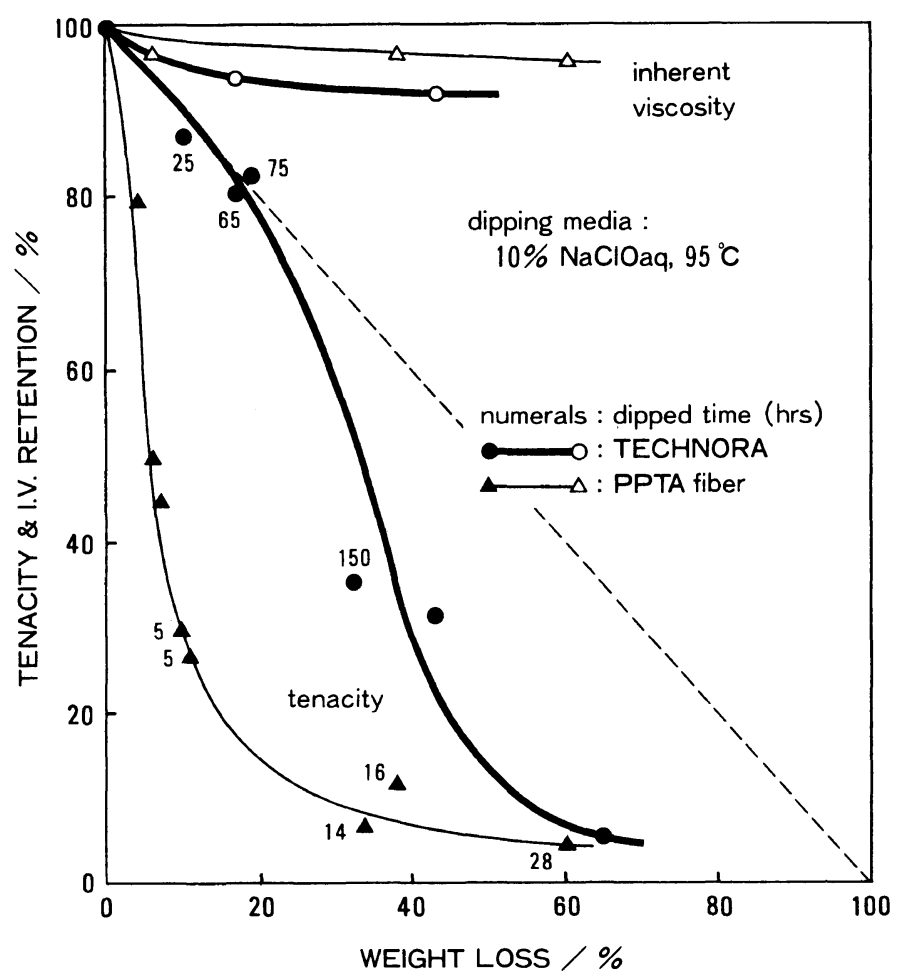

Figure 7. Tenacity retention and degradation of aramid fibers in oxidative media.

Therefore, at every boundary the crystallites are surfaced by highly stressed tie molecules, which are susceptible both to the chemical attack and the mechanical stresses, or by the chain ends which do not contribute to the fiber strength. In case of TECHNORA ${ }^{\circledR}$, on the other hand, the molecular chains are so much flexible and the crystallites are rather loose that the internal stresses upon drawing may have been mostly dissipated during the process. Thus, there will be less distinct boundary around the loose crystallites.

Moisture regain of the fibers is roughly proportional to the relative humidity of the environment. ${ }^{15}$ The values, equilibrated to RH $65 \%$, are: $2 \%$ for TECHNORA ${ }^{\circledR}, 4-6 \%$ for PPTA fibers. If one assumes water molecules to be absorbed only by the surface amide groups, the above data would mean that PPTA fibers have more than twice as much wider internal surface than does TECH-
Table IV. Permeability of small molecules across HM-50 membranes ${ }^{a}$

\begin{tabular}{lcc}
\hline & \multicolumn{2}{c}{ Membrane } \\
\cline { 2 - 3 } & As cast & Drawn $(\times 1.5)$ \\
\hline Thickness $(\mathrm{mm})$ & 0.029 & 0.020 \\
Density $\left(\mathrm{g} \mathrm{ml}^{-1}\right)$ & 1.3375 & 1.3755 \\
\hline Permeate gas & Permeability $\left(\mathrm{ml} \cdot \mathrm{cm} \mathrm{cm}^{-2} \cdot \mathrm{s} \cdot \mathrm{mmHg}\right)$ \\
$\mathrm{H}_{2} \mathrm{O}$ & $3.7 \times 10^{-11}$ & $4.0 \times 10^{-12}$ \\
$\mathrm{O}_{2}$ & $1.5 \times 10^{-12}$ & $1.4 \times 10^{-13}$ \\
$\mathrm{~N}_{2}$ & $2.6 \times 10^{-13}$ & $3.9 \times 10^{-14}$ \\
\hline
\end{tabular}

a Method: JIS Z 1707 (1975).

NORA $^{\circledR}$. If this is derived from the internal microfibrils, one can explain the difference of the two fibers in the chemical resistance as well as the frictional resistance and fatigue in the same term.

Since TECHNORA ${ }^{\circledR}$ fiber has been thought to be rather uniform in its texture, permea- 
bility of small molecules across cast and axially drawn membranes was studied for better understanding of its unique chemical resistance. The data in Table $\mathrm{IV}^{16}$ show that only by $50 \%$ stretch the membrane reduces its permeability by one order of magnitude. Inside of TECHNORA ${ }^{\circledR}$ fibers, usually drawn by 10 times of its original length, migration of small molecules or ions is presumably much suppressed by the highly oriented but not-toomuch strained polymer chains, which prevent themselves from progressive attack by chemicals.

Acknowledgements. The author wishes to express thanks to $\mathrm{Mr}$. H. Itagaki for his permission to publish this work, to Mr. T. Fukushima for his encouragement and supply of reference materials, to Dr. S. Hiratsuka for his assistance in access to various data, and to Mr. K. Iwata for the laborious membrane experiments.

\section{REFERENCES}

1. S. Ozawa, Preprints for $82 / 2$ Lecture Series, Soc.
Polymer Sci., Japan, p 30 (Oct., 1982).

2. A. G. Bayer, Japan Patent (Tokukai) 48-35117 (May 22, 1973).

3. K. Matsuda, unpublished.

4. L. B. Sokolov, V. D. Gerasimov, V. M. Savinov, and V. K. Belyakov, "Thermally Stable Aromatic Polyamides (Russian)," Izdatelstov, Ximiya, Moscow, 1975.

5. Y. Nakagawa, unpublished.

6. E. I. du Pont, Japan Patent (Tokukai) 55-48217 (April 5, 1980, prior. Aug. 7, 1978).

7. a) T. Jinda, T. Noyori, and T. Matsuda, Seni Gakkai Shi (Japan), 39, T160 (1983); b) T. Jinda and T. Matsuda, ibid., 41, T87 (1985).

8. a) Teijin Limited, Japan Patent (Tokukai) 51-76386, $-134743,-136916,52-98795$ and U. S. Patent 4,075,172 (prior. Dec. 27, 1974); b) K. Kazama, "Preprints for Plastics Engineering Forum, The Society of Polymer Science, Japan," Mar., 1981, p 3.

9. a) A. Takagi, Kasen Geppo, No. 2, 64 (1986); b) M. Kamiyoshi, Plastics, 36, No. 3, 26 (1985).

10. T. Takada, Zairyo Kagaku, 21, 348 (1985).

11. Y. Nakagawa, unpublished.

12. M. Kamiyoshi, unpublished.

13. K. Matsuda, T. Nishikawa, and T. Watanabe, The 1984 International Chemical Congress of Pacific Basin, 09P02.

14. C. O. Pruneda, W. J. Steel, R. P. Kershaw, and P. J. Morgan, ACS Polym. Prepr., 22, 216 (1981).

15. A. Aoki and T. Takada, unpublished.

16. T. Yamada, unpublished. 